\title{
Effects of Cu addition on microstructure and mechanical properties of as-cast Mg-6Zn magnesium alloy
}

\section{Yu Zhang, *Xiao-feng Huang, Ying Ma, Ti-jun Chen, Yuan-dong Li and Yuan Hao}

State Key Laboratory of Advanced Processing and Recycling of Nonferrous Metals, Lanzhou University of Technology, Lanzhou 730050, China

\begin{abstract}
The application of Mg-Zn binary alloys is restricted due to their developed dendritic microstructure and poor mechanical properties. In this study, an alloying method was used to improve the mechanical properties of $\mathrm{Mg}-\mathrm{Zn}$ alloy. The Mg- $6 \mathrm{Zn}$ magnesium alloys microalloyed with varying $\mathrm{Cu}$ content $(0,0.8,1.5,2.0$ and $2.5 \mathrm{wt} . \%)$ were fabricated by permanent mould casting, and the effects of $\mathrm{Cu}$ content on the microstructure and mechanical properties of as-cast Mg- $6 \mathrm{Zn}$ alloys were studied using OM, SEM, XRD and tensile tests at room temperature. The obtained results show that the addition of Cu not only can refine the grains effectively, but also can modify the eutectic morphology and improve the mechanical properties of the alloys. The main phases of the studied alloys include $\alpha-M g, \mathrm{MgZn}_{2}, \mathrm{Mg}_{2} \mathrm{Cu}$ and $\mathrm{CuMgZn}$. When the content of $\mathrm{Cu}$ exceeds $0.8 \mathrm{wt} . \%, \mathrm{Mg}_{2} \mathrm{Cu}$ phase appears. Meanwhile, the eutectic morphology is modified into dendritic shape or lamellar structure, which has an adverse effect on the tensile properties. Furthermore, among the investigated alloys, the alloy containing $0.8 \%$ Cu shows an optimal ultimate tensile strength of $196 \mathrm{MPa}$, while the alloy with $1.5 \mathrm{wt} . \% \mathrm{Cu}$ obtains an excellent elongation of $7.22 \%$. The experimental alloys under different $\mathrm{Cu}$ contents show distinguishing fracture behaviors: the fracture of the alloy with $0.8 \mathrm{wt} . \% \mathrm{Cu}$ reveals a mixed mode of inter-granular and quasi-cleavage, while in other investigated alloys, the fracture behaviors are dominated by cleavage fracture.
\end{abstract}

Key words: Mg-Zn magnesium alloy; Cu addition; microstructure; mechanical property; fracture mode
CLC numbers: TG146.22
Document code: A
Article ID: 1672-6421(2017)04-251-07

F or decades, magnesium alloys have wide applications in the aerospace, transportation and mobile electronics industries due to their advantages such as extremely low density and good damping capacity, high specific strength and stiffness, excellent machinability and good castability ${ }^{[1-4]}$. However, commercial magnesium alloys provide limited mechanical properties, which hinder their widespread applications ${ }^{[5]}$. More particularly, to the best of our knowledge, the Mg-Zn binary alloys possess coarse dendritic microstructures, extensive hot cracking tendency, critical shrinkage cavities and porosities. These drawbacks will significantly worsen the mechanical properties of the alloy ${ }^{[6]}$. The improvement of mechanical properties is a severe and urgent challenge in magnesium alloys research fields. He et al. ${ }^{[7]}$ found that the mechanical properties of magnesium alloys can be significantly improved via appropriate microalloying due

\section{*Xiao-feng Huang}

Male, born in 1971, Ph. D, Associate professor. Research interests: magnesium alloys and semi-solid forming. To date, he has published over 70 papers..

E-mail: huangxf_lut@163.com

Received: 2016-12-16; Accepted: 2017-04-03 to grain refinement and microstructure modification in the as-cast condition. In order to improve the microstructure and mechanical properties of $\mathrm{Mg}-\mathrm{Zn}$ binary alloys, many attempts have been devoted to the research and development of high-performance new $\mathrm{Mg}-\mathrm{Zn}$ based alloys. For example, Mg-Zn-Zr, Mg-Zn-RE, Mg-Zn-Cu and $\mathrm{Mg}-\mathrm{Zn}-\mathrm{Al}-\mathrm{Mn}$ alloy systems have been developed and widely applied for some industrial products. There are some minor alloying element investigations in $\mathrm{Mg}-\mathrm{Zn}$ binary alloys, for instance, adding $\mathrm{Ag}, \mathrm{Zr}$, rare earth (RE) or $\mathrm{Cu}$ to the $\mathrm{Mg}-\mathrm{Zn}$ alloy system ${ }^{[8]}$. It is noteworthy that $\mathrm{Cu}$ is a cost-effective element, compared with some rare earth elements such as $\mathrm{Ce}, \mathrm{Nd}, \mathrm{Y}$ and $\mathrm{Gd}^{[9]}$. Meanwhile, the $\mathrm{Cu}$ plays a favorable role in improving the mechanical properties of magnesium alloys. It is well recognized that the addition of $\mathrm{Cu}$ not only can considerably improve the castability, but also it effectively increases the eutectic temperature of the alloy so as to complete the dissolution of solute atoms at higher temperatures ${ }^{[10-11]}$. Furthermore, the dissolved $\mathrm{Cu}$ atoms can apparently promote the nucleation and restrain the grain growth as well as increase precipitate concentration during aging treatment. It has been 
reported that the $\mathrm{Mg}-\mathrm{Zn}-\mathrm{Cu}$ alloys exhibit relatively high ductility and high strength owing to the grain refinement caused by $\mathrm{Cu}$ and $\mathrm{Zn}{ }^{[12]}$. $\mathrm{Zhu}$ et al. ${ }^{[13]}$ investigated the effects of $\mathrm{Cu}$ addition on microstructure and mechanical properties of ascast magnesium alloy ZK60. The results indicated that the alloy modified with trace $\mathrm{Cu}$ of $(0.5-1)$ wt.\% exhibits the optimal mechanical properties with an excellent elongation of over $9 \%$. Therefore, it is feasible to forecast that the reasonable addition of $\mathrm{Cu}$ should play a beneficial role in the grain refinement and improvement of mechanical properties for $\mathrm{Mg}-\mathrm{Zn}$ binary alloys at room temperature. Although the previously mentioned studies about $\mathrm{Cu}$-containing magnesium alloys have been reported widely, the effects of $\mathrm{Cu}$ addition on the eutectic morphology and relationship between eutectic morphology and mechanical properties of as-cast $\mathrm{Mg}-6 \mathrm{Zn}$ based alloys have been investigated rarely. Hence, in this study, $\mathrm{Mg}-6 \mathrm{Zn}-x \mathrm{Cu}$ alloys $(x=0,0.8,1.5,2.0$ and $2.5 \mathrm{wt} . \%)$ microalloyed with different contents of $\mathrm{Cu}$ were designed and investigated systematically, so as to provide a serviceable basis for developing new low-cost $\mathrm{Cu}$-containing magnesium alloys.

\section{Experimental procedure}

The Mg-6Zn based alloys with different $\mathrm{Cu}$ contents $(0,0.8,1.5$, 2.0 and $2.5 \%$, in weight percent unless stated otherwise) were prepared from commercial high purity $\mathrm{Mg}$ (>99.99\%), Zn ingot $(>99.999 \%)$ and $\mathrm{Cu}$ sheet (>99.99\%). All the raw alloys were preheated to $200{ }^{\circ} \mathrm{C}$, and then the pure $\mathrm{Mg}$ ingot was melted in an electric resistance furnace with a mild steel crucible under protection of Ar atmosphere and a covering agent RJ-2. After the pure $\mathrm{Mg}$ ingot was completely melted, the $\mathrm{Zn}$ ingot was added into the melt. When the melt temperature was increased to approximately $720^{\circ} \mathrm{C}$, the $\mathrm{Cu}$ lump was added to the melt. Then the melt was held at $750{ }^{\circ} \mathrm{C}$ for $20 \mathrm{~min}$ for the homogenization of alloying elements. Subsequently, $2 \%$ (ratio to the whole raw metal) $\mathrm{C}_{2} \mathrm{Cl}_{6}$ was added to the melt by mechanical stirring for deslagging at $730{ }^{\circ} \mathrm{C}$. After refining, the melt was isothermally maintained for $20 \mathrm{~min}$ at this temperature for the settlement of inclusions, and then, at $710^{\circ} \mathrm{C}$, was poured into the metallic mold preheated to $200{ }^{\circ} \mathrm{C}$.

Metallographic specimens for microstructural observation were cut from the same position of each cast ingot with the dimension of $15 \mathrm{~mm}$ in diameter and $180 \mathrm{~mm}$ in length, and then mechanically polished according to standard metallographic technique, followed by etching using a $4 \mathrm{vol} . \% \mathrm{HNO}_{3}$ solution in $\mathrm{C}_{2} \mathrm{H}_{5} \mathrm{OH}$ at room temperature. Then the specimens were observed using a MeF-3 optical microscope (OM) and field emission scanning electron microscope (SEM) with energy dispersive spectroscope (EDS). The phase constituents were identified by a D/max-2400 X-ray diffraction (XRD) using a $\mathrm{Cu}$ $\mathrm{K} \alpha$ radiation with a scanning velocity of $5 \% \mathrm{~min}$ and a scanning angle from 10 to $90^{\circ}$. The tensile specimens (a cross-section of 2 $\mathrm{mm} \times 3 \mathrm{~mm}$ and a gauge length of $15 \mathrm{~mm}$ ) were processed from the bottom of the obtained slabs utilizing a computer numericalcontrolled wire-cutting machine, as shown in Fig. 1. The mechanical tests were performed on a WDW-100D universal material testing machine with a loading rate of $1 \mathrm{~mm} \cdot \mathrm{s}^{-1}$ at room temperature. The average of three tensile specimens was taken as ultimate tensile strength (UTS) and elongation to fracture (Ef) for each alloy. Tensile specimens for fracture observation were also conducted using SEM.
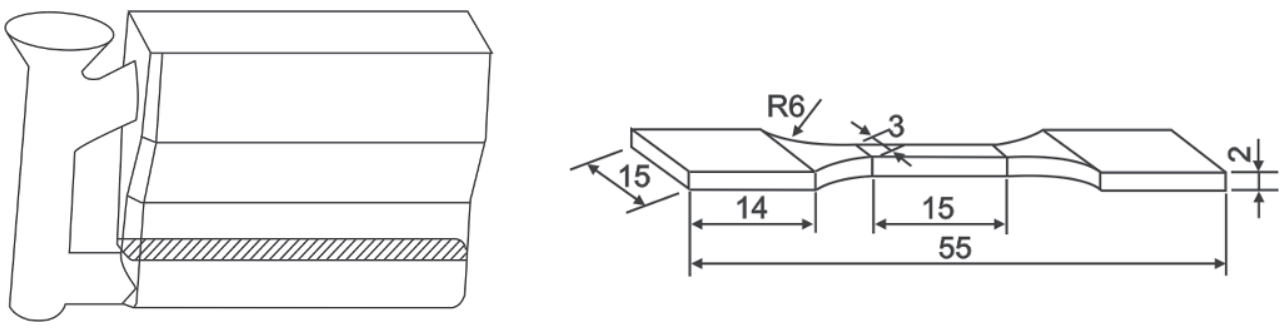

Fig. 1: Schematic for cast ingot and tensile test sample (unit: $\mathrm{mm}$ )

\section{Results and discussion}

\subsection{As-cast microstructure}

The XRD results of as-cast $\mathrm{Mg}-6 \mathrm{Zn}$ alloys containing different $\mathrm{Cu}$ contents are shown in Fig. 2. It can be seen that the $\mathrm{Mg}-6 \mathrm{Zn}$ alloy consists of $\alpha-\mathrm{Mg}$ and $\mathrm{MgZn}_{2}$ phases with a base-centered monoclinic structure ( $a=2.596 \mathrm{~nm}, b=1.428 \mathrm{~nm}, c=0.524 \mathrm{~nm}$, $\left.\gamma=102.5^{\circ}\right)^{[14]}$. The alloy with $0.8 \% \mathrm{Cu}$ consists of three phases, i.e., $\alpha-\mathrm{Mg}, \mathrm{MgZn}_{2}$ and $\mathrm{CuMgZn}$ phases. When the content of $\mathrm{Cu}$ exceeds $0.8 \%$, the $\mathrm{Cu}$-containing alloys not only include $\alpha-\mathrm{Mg}, \mathrm{MgZn}_{2}$ and $\mathrm{CuMgZn}$ phases, but also contain additional diffraction peaks of $\mathrm{Mg}_{2} \mathrm{Cu}$ phase. In addition, the number of $\mathrm{Mg}_{2} \mathrm{Cu}$ and $\mathrm{CuMgZu}$ peaks increases with the increasing $\mathrm{Cu}$ content. The $\mathrm{CuMgZn}$ phase has a face-center cubic structure ( $a$ $=0.7169 \mathrm{~nm}$, space group Fd 3m) ${ }^{[15]}$.

The $\mathrm{OM}$ of as-cast $\mathrm{Mg}-6 \mathrm{Zn}$ alloys with different $\mathrm{Cu}$ additions is shown in Fig. 3. It can be clearly seen that all investigated alloys feature a typical non-equilibrium solidification microstructure, which is composed of matrix $\alpha-\mathrm{Mg}$, eutectic compounds and a few isolated particles distributed inside the grain. The obvious differences for the distribution of eutectic phases are observed among the alloys, namely, the distribution of eutectic phases is gradually changed from semi-continuous into completely continuous net-work morphology with increasing $\mathrm{Cu}$ content. In addition, the size of grains is obviously refined with an increment of $\mathrm{Cu}$ addition. 


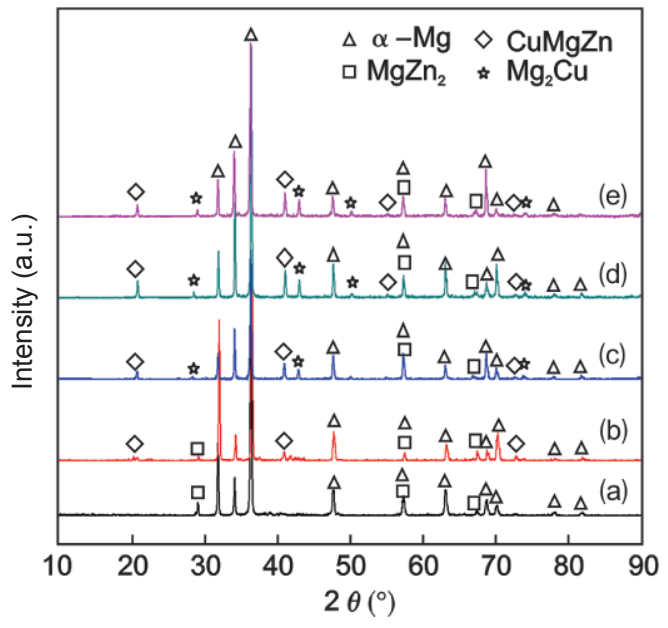

Fig. 2: XRD patterns of as-cast Mg-6Zn- $x$ Cu alloys: (a) $x=0$; (b) $x=0.8$; (c) $x=1.5$; (d) $x=2.0$; (e) $x=2.5$
The microstructure of the $\mathrm{Cu}$-free alloy (Fig. 3a) consists of $\alpha-\mathrm{Mg}$, secondary phases and some isolated particles within the primary dendrites. The secondary phases with continuous or semi-continuous morphology distribute along the grain boundaries. When the $0.8 \% \mathrm{Cu}$ is added to $\mathrm{Mg}-6 \mathrm{Zn}$ alloy, as shown in Fig. 3(b), the amount of continuous eutectic phases obviously increases, meanwhile, the microstructure is slightly refined. With $1.5 \% \mathrm{Cu}$ addition, it can be found from Fig. 3(c) that the microstructure contains $\alpha-\mathrm{Mg}$, continuous eutectic phases and a large amount of isolated particles inside the grains. The primary $\alpha-\mathrm{Mg}$ grains show two different types of morphologies: the large dendritic grain (marked by $\alpha 1$ ) and the small granular grain (marked by $\alpha 2$ ). The secondary dendritic arm spacing (SDAS) is increased markedly, the size of grains further decreases while the eutectic phases evidently increase
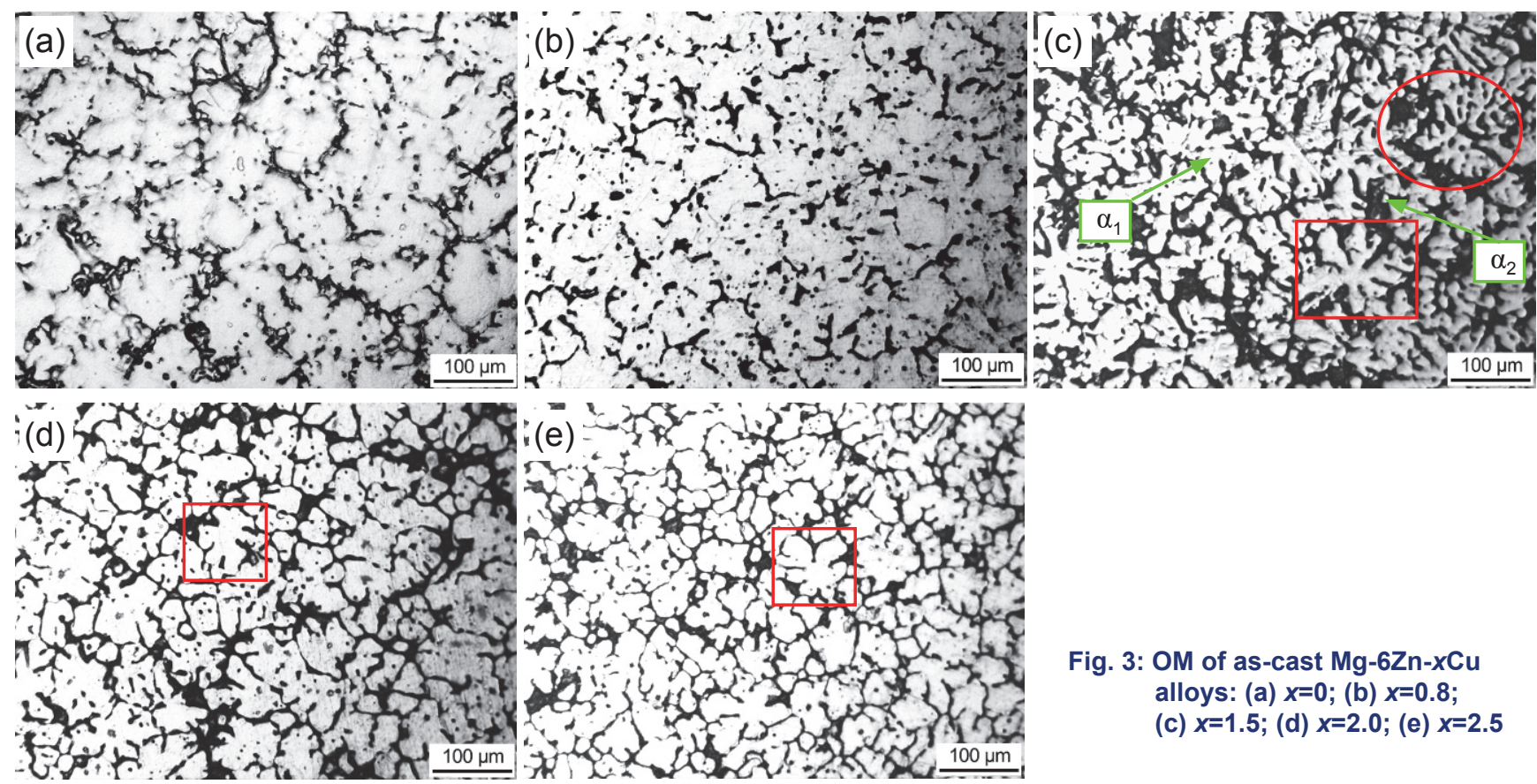

Fig. 3: OM of as-cast $\mathrm{Mg}-6 \mathrm{Zn}-\mathrm{xCu}$ alloys: (a) $x=0$; (b) $x=0.8$; (c) $x=1.5$; (d) $x=2.0$; (e) $x=2.5$

(comparing Fig. 3b), which is consistent with the results of the XRD analysis (Fig. 2c). According to the XRD patterns, the increased phases should be $\mathrm{CuMgZn}$ and $\mathrm{Mg}_{2} \mathrm{Cu}$. In addition, there are some eutectic phase clusters at local regions (marked by elliptical circles). When the content of $\mathrm{Cu}$ is continuously increased to $2.0 \%$, the morphology of the eutectic phases is modified completely into continuous net-work form. Similarly, the primary grains with different morphologies can still be found. Furthermore, the size of grains decreases further, as compared to the alloy with $1.5 \% \mathrm{Cu}$. Further increasing $\mathrm{Cu}$ content to $2.5 \%$, it can be clearly seen from Fig. 3(e) that the grain size of the alloy is the smallest among those of the given alloys (comparing Fig. 3a-d). The massive eutectic phases tend to distribute around grain boundaries. This is mainly due to the fact that more $\mathrm{Cu}$ addition can alter kinetics of precipitation reaction, resulting in the improvement of the driving force of nucleation, which increases the amount of precipitates ${ }^{[16]}$. The SDAS and the number of the independently primary $\alpha-\mathrm{Mg}$ grains increase dramatically. Meanwhile, the primary $\alpha-M g$ grains with different morphologies are also observed in the alloy.

It is obvious that the grain sizes of the as-cast alloys are distinctly affected by $\mathrm{Cu}$ content. That is to say, increasing the amount of added $\mathrm{Cu}$, the grain refinement tendency of $\mathrm{Mg}-6 \mathrm{Zn}$ alloys intensifies (Fig. 3). This can be explained by the following reasons. On one hand, the addition of $\mathrm{Cu}$ can alter the solidus of the alloys, which shortens the solidification time and thus refines the microstructure ${ }^{[17]}$. On the other hand, the $\mathrm{CuMgZn}$ intermetallic compound possesses high melting point and good thermal stability ${ }^{[18]}$. The CuMgZn phase plays a heterogeneous nucleation substrate role in the process of solidification, which efficiently promotes the formation of crystal nucleus and thus refines grains. This stimulation effect will be improved as the added $\mathrm{Cu}$ content increases. In summary, the refinement efficiency of an element can be estimated by the grain refinement factor (GRF) ${ }^{[19]}$. It can be described by the following expression: $\Sigma_{i} m_{i} C_{o, i}\left(k_{i}-1\right)$, where $m_{i}$ is the slope of the liquidus line in the binary phase diagram, $C_{o, i}$ is the initial concentration 
of element $i$ and $k_{i}$ is the solute distribution coefficient. According to the $\mathrm{Mg}-\mathrm{Cu}$ binary phase diagram, $m_{\mathrm{Cu}}$ and $k_{\mathrm{Cu}}$ are -5.37 and 0.02 , respectively. Therefore, the GRF value increases when the concentration of the element $\mathrm{Cu}$ is increased. Based on this viewpoint, it is easy to comprehend the decrease of grain size with the increase of $\mathrm{Cu}$ content from $0 \%$ to $2.5 \%$. A large GRF not only implies large hindering effect on crystal growth, but also means that the growing crystal can generate large constitutional supercooling quickly and thus accelerate the formation of stable nuclei ${ }^{[20]}$.

As can be seen from Fig. 3, the SDAS firstly decreases as the $\mathrm{Cu}$ content increases from 0 to $0.8 \%$, then increases when the $\mathrm{Cu}$ content exceeds $0.8 \%$. The evolution tendency is considered to be related to the following reasons. The SDAS can be evaluated by the following equations ${ }^{[21]}$ :

$$
\begin{gathered}
\lambda_{2}=5.5\left(M t_{f}\right)^{\frac{1}{3}} \\
M=\frac{\Gamma D \ln \left(\frac{C_{l}^{m}}{C_{0}}\right)}{m(1-k)\left(c_{0}-c_{l}^{m}\right)}
\end{gathered}
$$

where $k$ can be calculated as: $k=\left(\frac{C_{s}}{C_{l}}\right)$

where $\lambda_{2}$ is the value of SDAS, $\mu \mathrm{m} ; t_{f}$ is the local solidification time, $\mathrm{s} ; \Gamma$ is the Gibbs Thomson; $D$ is the diffusion coefficient in liquid, $\mathrm{m}^{2} \cdot \mathrm{s}^{-1} ; m$ is the liquid slope, $\mathrm{K} / \mathrm{wt} . \% ; M$ is the volume coarsening rate of the dendritic arm, $\mathrm{m}^{3} \cdot \mathrm{s}^{-1} ; C_{0}$ is the initial alloy concentration, wt. $\% ; C_{l}^{m}=C_{e}$, the eutectic composition, wt.\%; $k$ is the distribution coefficient; $C_{s}$ and $C_{l}$ are the equilibrium solubility. As is well known, the as-cast grain sizes are closely related to the degree of heterogeneous nucleation and the constitutional undercooling ${ }^{[22]}$. When $0.8 \% \mathrm{Cu}$ is added to the melt, $\mathrm{Cu}$ atoms will be squeezed out of the liquid ahead of the growing interface for a relatively rapid cooling rate during solidification process. As a result, it increases the solid-liquid interfacial energy, prevents the diffusion of $\mathrm{Zn}$ atoms, and then increases the value of $C_{l}$. According to eq. (2) and (3), the increase of $C_{l}$ results in the decrease of $k$, and then the reduction of $k$ leads to the decrease of $M$. Consequently, according to eq. (1), when $0.8 \% \mathrm{Cu}$ is added to the alloy, $\lambda_{2}$ decreases distinctly, as compared to the alloy without $\mathrm{Cu}$. On the contrary, when the addition of $\mathrm{Cu}$ is more than $0.8 \%$, $\mathrm{Mg}_{2} \mathrm{Cu}$ phase appears; meanwhile, the number of $\mathrm{CuMgZn}$ and $\mathrm{Mg}_{2} \mathrm{Cu}$ phases tends to increase (Fig. 2c-2e), with the result that massive $\mathrm{Cu}$ atoms are inevitably expended due to the generation of the increased $\mathrm{Cu}$-containing intermetallics during the solidification process. After these phases are formed, the grain growth will continue to proceed, while the amount of new nuclei tends to decrease because of the decrease of constitutional undercooling. Therefore, excessive $\mathrm{Cu}(>0.8 \%)$ addition leads to the increase of the SDAS.

The high-magnification SEM micrographs and the corresponding EDS analysis of the as-cast alloys are given in Fig. 4 and Table 1, respectively. As shown in Fig. 4, the eutectic morphology of the investigated alloys is evidently affected by $\mathrm{Cu}$ content. In the $\mathrm{Cu}$-free alloy, the eutectic compound shows smooth island morphology (Fig. 4a). The bright precipitate (marked A, D, H, K and O) of the alloy is rich in $\mathrm{Zn}$. Combined with the XRD results, the bright compound is confirmed to be $\mathrm{MgZn}_{2}$ phase. The gray precipitate (marked $\mathrm{B}$ ) in the $\mathrm{Cu}$ free alloy mainly contains $\mathrm{Mg}$; it is identified as $\alpha-\mathrm{Mg}$ and $\mathrm{MgZn}_{2}$ phase. The eutectic morphology of the alloy with $0.8 \%$ $\mathrm{Cu}$ presents flower pattern (Fig. 4b). Based on the results of the XRD, EDS and Table 1, the black area (marked C, F, I and $\mathrm{M}$ ) is regarded as $\alpha-\mathrm{Mg}$ phase, and the gray area (marked E) is identified as CuMgZn phase. With the addition of $1.5 \%$ $\mathrm{Cu}$, the eutectic phases change into perfect penniform shape (Fig. 4c). As seen in Table 1, the gray one (marked G) includes $\mathrm{Mg}, \mathrm{Zn}$ and $\mathrm{Cu}$, and is rich in $\mathrm{Cu}$ (comparing points $\mathrm{F}$ and $\mathrm{H}$ ), combining with the $\mathrm{XRD}$ results, it is regarded as $\mathrm{Mg}_{2} \mathrm{Cu}$ and $\mathrm{CuMgZn}$ phase. After $2 \% \mathrm{Cu}$ is added, the secondary phases present lamellar or dendtitic morphology (Fig. 4d), but the gray precipitates (marked $\mathrm{J}$ and $\mathrm{L}$ ) have similar constituents as that of the alloy with $1.5 \% \mathrm{Cu}$, which are also $\mathrm{Mg}_{2} \mathrm{Cu}$ and $\mathrm{CuMgZn}$ phases. When the $\mathrm{Cu}$ content is up to $2.5 \%$, the whole eutectic morphology of the alloy is clearly modified; the gray intermetallics display coarsely lamellar structure (Fig. 4e). The constituent of the gray precipitate (marked $\mathrm{N}$ ) is inferred as $\mathrm{Mg}_{2} \mathrm{Cu}$ and $\mathrm{CuMgZn}$ phase according to the XRD. According to the formation mechanism of the lamellar structure reported by $\mathrm{Du}$ et al ${ }^{[23]}$, it is reasonable to assume that the creation of lamellar structure of the alloy with more $\mathrm{Cu}(\geqslant 2.0 \%)$ is due to the addition of $\mathrm{Cu}$ causing intensive constitutional undercooling ahead of the solid/liquid interface in the liquid layer, promoting the primary $\alpha-\mathrm{Mg}$ phase solidification and the increase of $\mathrm{Cu}$ and $\mathrm{Zn}$ concentration in the liquid. As a result, the composition ahead of the solid/liquid interface attains the eutectic composition and matches within a zone of the coupled eutectic growth. Therefore, the addition of more $\mathrm{Cu}$ promotes to the formation of a lamellar morphology of the intermetallics.

\subsection{Mechanical properties}

Mechanical properties have an important relationship with the amount and distribution of the intermetallics ${ }^{[24]}$. Trace addition of $\mathrm{Cu}$ to the $\mathrm{Mg}$-6Zn alloys causes the modification of the intermetallics morphology, which will accordingly affect the mechanical properties. Figure 5 shows the variations of the room temperature tensile properties of $\mathrm{Mg}-6 \mathrm{Zn}$ alloys with different $\mathrm{Cu}$ contents, including the ultimate tensile strength (UTS) and elongation to fracture (Ef). As shown in Fig. 5, the addition of $\mathrm{Cu}$ has a positive effect on the tensile properties of the investigated alloys. The considerable improvement of the tensile properties is observed, as compared to the alloy without $\mathrm{Cu}$. It is found that the UTS and Ef firstly increase as the $\mathrm{Cu}$ content increases, and then decrease. When the $0.8 \%$ $\mathrm{Cu}$ is added to $\mathrm{Mg}-6 \mathrm{Zn}$ alloy, the UTS increases sharply to the maximum value of $196 \mathrm{MPa}$, but the Ef does not reach the peak value. Contrarily, when the content of $\mathrm{Cu}$ is increased to $1.5 \%$, a peak value $7.22 \%$ of Ef is obtained. Compared with the $\mathrm{Cu}$-free alloy, the peak values of UTS and Ef are enhanced by $16 \mathrm{MPa}$ and $24.5 \%$, respectively. It is well known that the fine grains are commonly beneficial to the tensile properties 

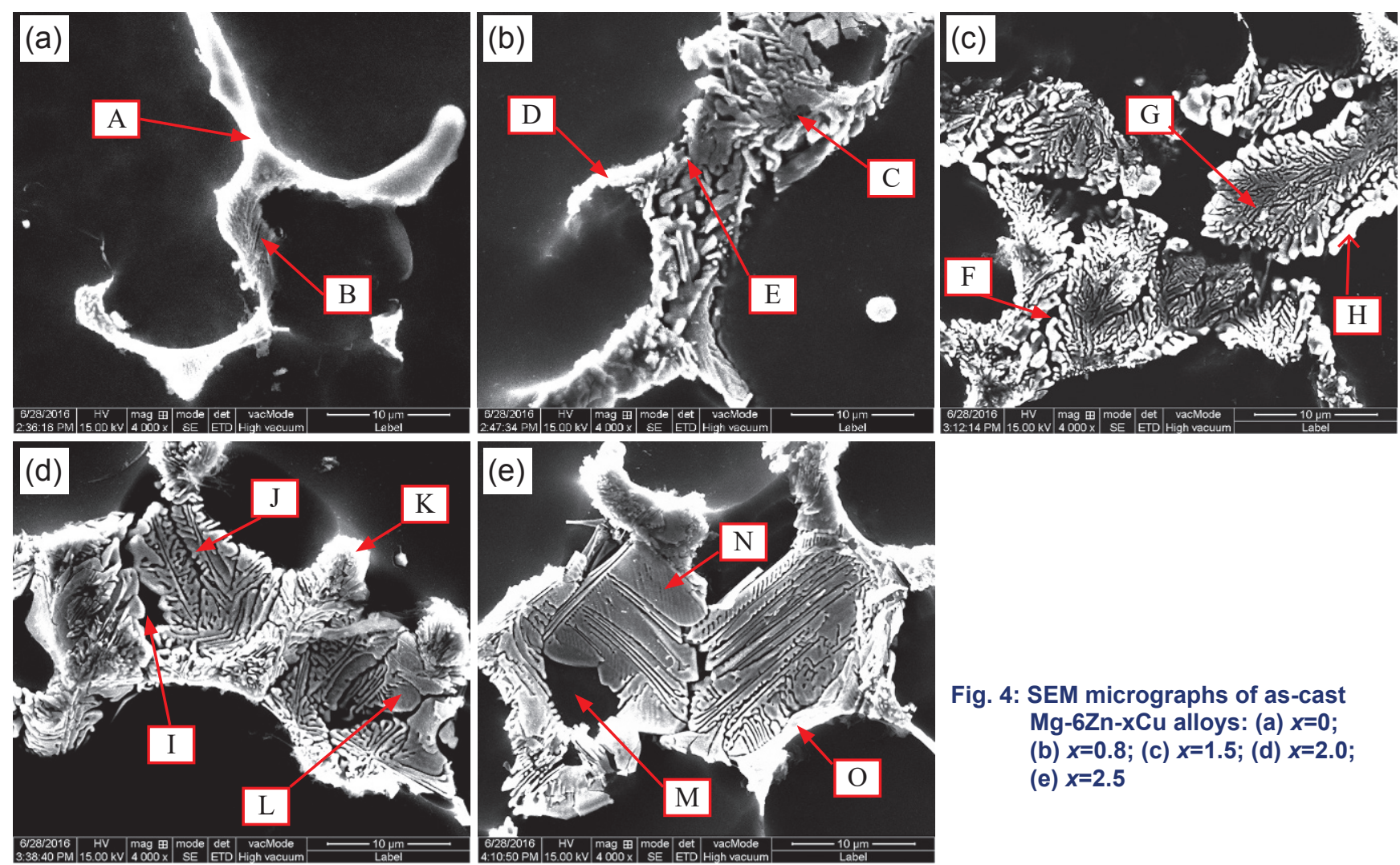

Fig. 4: SEM micrographs of as-cast Mg- $6 Z n-x C u$ alloys: (a) $x=0$;

(b) $x=0.8$; (c) $x=1.5$; (d) $x=2.0$; (e) $x=2.5$

Table 1: Chemical compositions of as-cast alloys (at.\%)

\begin{tabular}{lccc} 
Location (point) & Mg & Zn & Cu \\
\hline Fig. 4(a), A & 65.20 & 34.80 & 0.00 \\
Fig. 4(a), B & 81.60 & 18.40 & 0.00 \\
Fig. 4(b), C & 97.50 & 1.70 & 0.80 \\
Fig. 4(b), D & 64.40 & 34.10 & 1.50 \\
Fig. 4(b), E & 78.60 & 13.10 & 8.30 \\
Fig. 4(c), F & 97.48 & 1.65 & 0.87 \\
Fig. 4(c), G & 75.40 & 14.10 & 10.50 \\
Fig. 4(c), H & 65.70 & 33.80 & 0.50 \\
Fig. 4(d), I & 97.30 & 2.70 & 0.00 \\
Fig. 4(d), J & 57.80 & 28.20 & 14.00 \\
Fig. 4(d), K & 68.17 & 31.10 & 0.73 \\
Fig. 4(d), L & 68.10 & 20.20 & 11.70 \\
Fig. 4(e), M & 98.40 & 1.60 & 0.00 \\
Fig. 4(e), N & 51.70 & 28.60 & 19.70 \\
Fig. 4(e), O & 64.08 & 35.10 & 0.82 \\
\hline
\end{tabular}

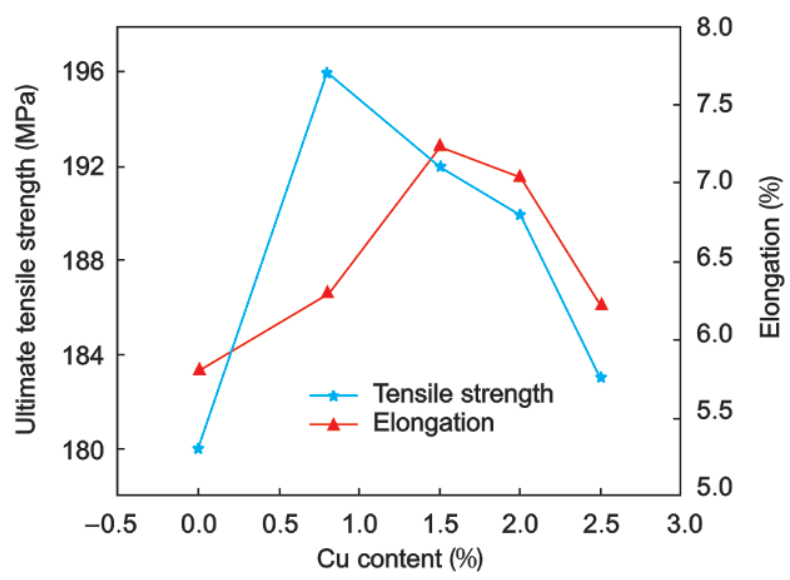

Fig. 5: Room-temperature tensile properties of as-cast $\mathrm{Mg}-6 \mathrm{Zn}-\mathrm{xCu}$ alloys

is due to that the $\mathrm{Cu}$ addition can offer a valuable solution to the microstructural inhomogeneity for the investigated alloys and effectively decrease the grain sizes of the alloys. When the content of $\mathrm{Cu}$ is over $0.8 \%$ and $1.5 \%$, the UTS and Ef have a trend to decline. The UTS and Ef decrease from peak values of $196 \mathrm{MPa}(0.8 \% \mathrm{Cu})$ and $7.22 \%(1.5 \% \mathrm{Cu})$ to $183 \mathrm{MPa}$ and $6.21 \%$, respectively, when $\mathrm{Cu}$ addition reaches $2.5 \%$. The degradation of tensile properties is mainly ascribed to the following two reasons: (1) A higher addition of $\mathrm{Cu}$ $(\geqslant 1.5 \%)$ causes the formation of the $\mathrm{Mg}_{2} \mathrm{Cu}$ compounds (Fig. 2) and increase of eutectic phase amounts. In addition, the eutectic morphology is modified into dendritic shape or lamellar structure, which acts as crack initiation sites during tensile testing, thus deteriorating the tensile properties. This

microstructural inhomogeneity has been an issue in many binary $\mathrm{Mg}-\mathrm{Zn}$ alloys ${ }^{[26]}$. The increase of tensile properties 
is mainly due to the fact that high stress concentration will be produced in the vicinity of a large number of second phases [27], which might cause the crack initiation and reduce the mechanical properties. (2) Furthermore, with the increment of $\mathrm{Cu}$ content, the primary $\alpha-\mathrm{Mg}$ grains are surrounded by the continuous agglomerates, which probably play an adverse role in increasing the tensile properties ${ }^{[28]}$. In a word, the dendritic shape or lamellar structure and continuous agglomerates are responsible for the decrease in the tensile properties. By comparison of the mechanical properties of the investigated alloys, it can be concluded that a proper content of $\mathrm{Cu}(0.8 \%$ $1.5 \%$ ) can dramatically enhance the tensile properties of the as-cast $\mathrm{Mg}-6 \mathrm{Zn}$ base alloys at room temperature.

\subsection{Fracture analysis}

The cleavage fracture, quasi-cleavage fracture and intergranular fracture are the main fracture modes of magnesium alloys ${ }^{[29]}$. Figure 6 shows the SEM images of tensile fracture surfaces of the studied alloys with different $\mathrm{Cu}$ contents. As shown in Fig. 6(a), in the alloy without $\mathrm{Cu}$, several porosities are found; meanwhile, some tear ridges and cleavage planes can also be observed. The generation of the porosities is attributed to molten metal being scarce in these areas. This is because the relatively rapid cooling rate leads to these porosities are not padded by the corresponding molten metal in the subsequent solidification process. The fracture surfaces of the alloy with $0.8 \% \mathrm{Cu}$ are characterized by many small cleavage facets, tear ridges, cleavage steps and some subtle dimples, indicating that the tensile fracture surfaces have mixed characteristics of inter-granular and quasi-cleavage fractures. In Fig. 6(c), a few cleavage planes and a small number of tearing ridges present and some porosities are also found in the local areas of tensile fracture surfaces for the alloy with $1.5 \% \mathrm{Cu}$. These porosities are possibly associated with oxide inclusions. With $2 \% \mathrm{Cu}$ addition, as shown in Fig. 6(d), the fracture surfaces mainly consist of a few ambiguous cleavage planes, tearing ridges and visible cracks. The cracks are possibly related to the dendritic morphology and lamellar structure of the eutectic phase of the alloy. Yang et al ${ }^{[30]}$ pointed out that the initiation of micro-cracks can be greatly influenced by the presence and nature of the secondary phases. Therefore, it can be speculated that the $\mathrm{Cu}$-bearing phase probably plays a potential role in the formation of the nucleation sites of microcracks. When the content of $\mathrm{Cu}$ is up to $2.5 \%$, as shown in Fig. 6(e), a small number of tearing ridges and massive cracks are observed. According to the fracture characteristics, the fracture behavior of the alloy is inter-granular pattern.
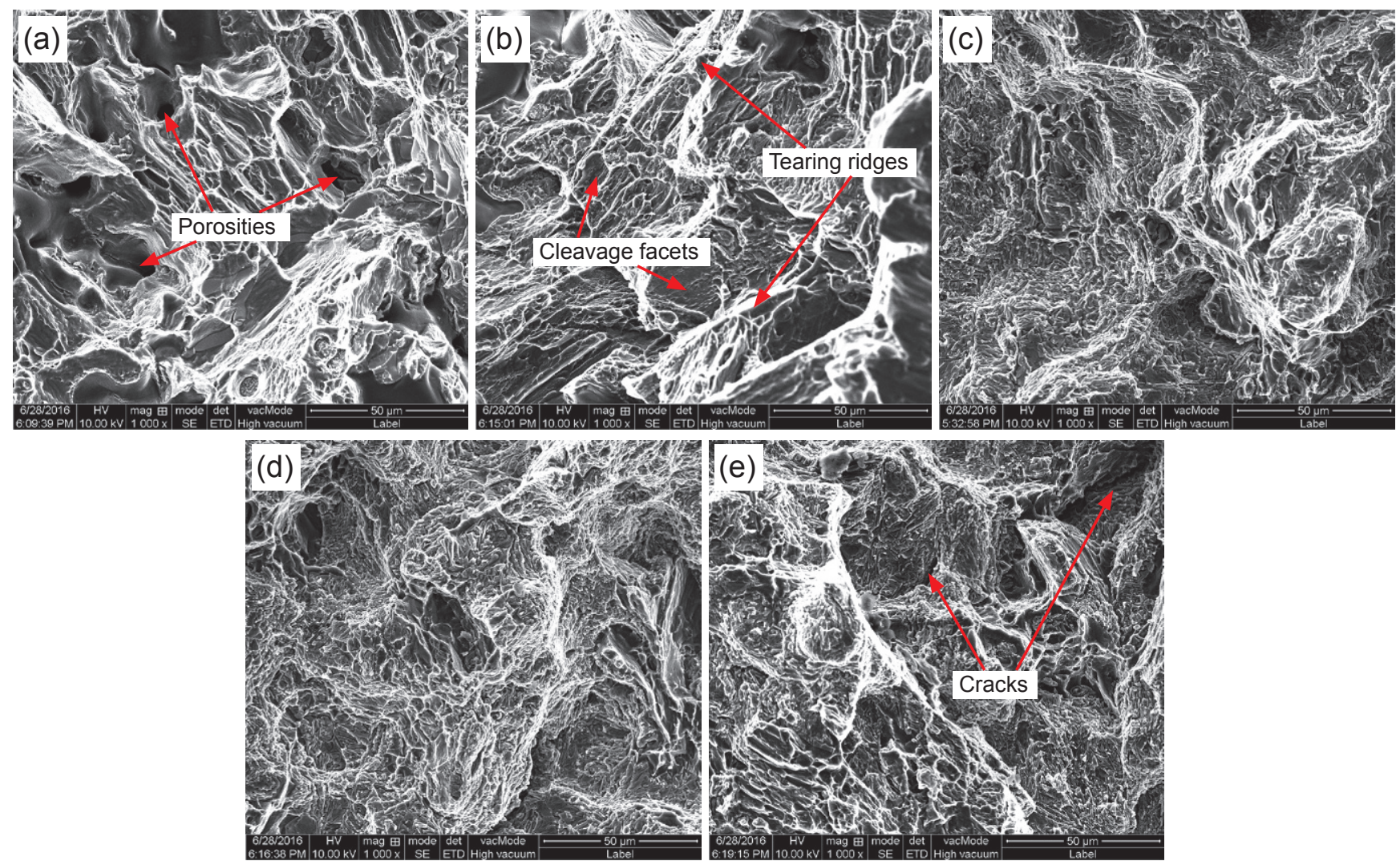

Fig. 6: SEM micrographs of tensile fracture surface of as-cast Mg- $6 \mathrm{Zn}-\mathrm{xCu}$ alloys: (a) $x=0$;

(b) $x=0.8$; (c) $x=1.5$; (d) $x=2.0$; (e) $x=2.5$

\section{Conclusions}

(1) The addition of $\mathrm{Cu}$ has significant effects on the phase constituent and microstructure of as-cast Mg-6Zn based alloys.
Varied phase constituents, including $\mathrm{MgZn}_{2}, \mathrm{Mg}_{2} \mathrm{Cu}$ and $\mathrm{CuMgZn}$, are obtained by adjusting the content of $\mathrm{Cu}$. The amount of eutectic compounds increases while the grain sizes gradually decrease with the incremental addition of $\mathrm{Cu}$. 
(2) $\mathrm{Cu}$ can modify the eutectic morphology from a smooth island (the base alloy) to flower pattern, perfectly penniform shape, lamellar or dendritic shape (with $0.8 \%-2.0 \% \mathrm{Cu}$ ), and then to coarsely lamellar structure (with $2.5 \% \mathrm{Cu}$ ). When the addition of $\mathrm{Cu}$ exceeds $0.8 \%$, the SDAS has a tendency to increase.

(3) The small amount of $\mathrm{Cu}(0.8 \%)$ addition results in considerable increases of the UTS, giving a maximum UTS value of $196 \mathrm{MPa}$, while a peak value of $\operatorname{Ef}(7.22 \%)$ is obtained when the content of $\mathrm{Cu}$ is $1.5 \%$. However, an excessive $\mathrm{Cu}$ addition $(\geqslant 1.5 \% \mathrm{Cu})$ will substantially deteriorate the tensile properties of the alloys.

(4) The experimental alloys under different $\mathrm{Cu}$ contents show different fracture behaviors: in $\mathrm{Mg}-6 \mathrm{Zn}-(0-2.5) \mathrm{Cu}$ alloy, the fracture behavior of the alloys reveals cleavage fracture while the alloy with $0.8 \% \mathrm{Cu}$ exhibits a mixed fracture of inter-granular and quasi-cleavage fracture with ductile rupture characterized by dimples, tear ridges and cleavage steps.

\section{References}

[1] Zhu H M, Luo C P, Liu J W, et al. Growth twinning behavior of cast $\mathrm{Mg}-\mathrm{Zn}-\mathrm{Cu}-\mathrm{Zr}$ alloys. Transactions of Nonferrous Metals Society of China, 2014, 24(2): 316-320.

[2] Wang W, Xu C X, Zhang J S, et al. Effects of Ce addition on microstructure, mechanical properties and corrosion resistance of as-cast AZ80 magnesium alloy. China Foundry, 2014, 11(3): 157162.

[3] Wang J F, Gao S, Song P F, et al. Effects of phase composition on the mechanical properties and damping capacities of as-extruded $\mathrm{Mg}-\mathrm{Zn}-\mathrm{Y}-\mathrm{Zr}$ alloys. Journal of Alloys and Compounds, 2011, 509(34): 8567-8572.

[4] Ming $Y$, Zheng $Z \mathrm{Q}$. Effects of $Z n$ on the microstructures and mechanical properties of $\mathrm{Mg}-3 \mathrm{Sm}-0.5 \mathrm{Gd}-x \mathrm{Zn}-0.5 \mathrm{Zr}(x=0,0.3$ and 0.6 ) alloy. Journal of Alloys and Compounds, 2014, 590: 355-361.

[5] Luo A A, Mishra R K, Powell B R, et al. Magnesium alloy development for automotive applications. Materials Science Forum, 2012, 706-709: 69-82.

[6] Chen Zhenhua. Magnesium Alloys. Beijing: Chemical Industry Press, 2004; pp. 312-313.

[7] He S M, Zeng X Q, Peng L M, et al. Microstructure and strengthening mechanism of high strength $\mathrm{Mg}-10 \mathrm{Gd}-2 \mathrm{Y}-0.5 \mathrm{Zr}$ alloy. Journal of Alloys and Compounds, 2007, 427(1-2): 316-323.

[8] Wei S H, Zhu T P, Michael H, et al. Effects of lead addition on the microstructure and mechanical properties of as-cast $\mathrm{Mg}-4 \mathrm{Zn}$ alloys. Materials Science and Engineering A, 2012, 550: 199-205.

[9] Yu H, Yu H S, Kin Y M, et al. Hot deformation behavior and processing maps of $\mathrm{Mg}-\mathrm{Zn}-\mathrm{Cu}-\mathrm{Zr}$ magnesium alloy. Transactions of Nonferrous Metals Society of China, 2013, 23(3): 756-764.

[10] LI Aiwen, LIU Jiangwen, WU Cuilan, et al. Age-hardening behavior and precipitates of as-cast Mg- $3 \mathrm{Zn}-1.5 \mathrm{Cu}-0.6 \mathrm{Zr} \mathrm{Mg}$ alloy. The Chinese Journal of Nonferrous Metals, 2010, 20(6): 1053-1059.

[11] Buha J. Mechanical properties of naturally aged Mg-Zn-Cu-Mn alloy. Materials Science and Engineering A, 2008, 489(1-2): $127-$ 137.
[12] Golmakaniyoon S, Mahmudi R. Microstructure and creep behavior of the rare-earth doped $\mathrm{Mg}-6 \mathrm{Zn}-3 \mathrm{Cu}$ cast alloy. Materials Science and Engineering A, 2011, 528(3): 1668-1677.

[13] Zhu H M, Luo C P, Liu J W, et al. Effects of Cu addition on microstructure and mechanical properties of as-cast magnesium alloy ZK60. Transactions of Nonferrous Metals Society of China, 2014, 24(3): 605-610.

[14] Zhang D F, Shi G L, Zhao X B, et al. Microstructure evolution and mechanical properties of $\mathrm{Mg}-x \% \mathrm{Zn}-1 \% \mathrm{Mn}(x=4,5,6,7,8,9)$ wrought magnesium alloys. Transactions of Nonferrous Metals Society of China, 2011, 21(1): 15-25.

[15] Chen X H, Liu L Z, Pan F S, et al. Microstructure, electromagnetic shielding effectiveness and mechanical properties of Mg-Zn-Cu-Zr alloys. Materials Science and Engineering B, 2015, 197: 67-74.

[16] Liao Y G, Han X Q, Zeng M X, et al. Influence of Cu on microstructure and tensile properties of $7 X X X$ series aluminum alloy. Materials and Design, 2015(66): 581-586.

[17] Buha J, Ohkubo T. Natural aging in Mg- $\mathrm{Zn}(-\mathrm{Cu})$ alloys. Metallurgical and Materials Transactions A, 2008, 39(9): 2259-2273.

[18] Zhu H M, Sha G, Liu J W, et al. Microstructure and mechanical properties of Mg- $6 \mathrm{Zn}-\mathrm{xCu}-0.6 \mathrm{Zr}$ (wt.\%) alloys. Journal of Alloys and Compounds, 2011, 509(8): 3526-3531.

[19] Lee Y C, Dahle A K, StJohn D H. The role of solute in grain refinement of magnesium. Metallurgical and Materials Transactions A, 2000, 31(11): 2895-2906.

[20] Dahle A K, Lee Y C, Nave M D. Development of the as-cast microstructure in magnesium-aluminium alloys. Journal of Light Metals, 2001(1): 61-72.

[21] Qiu H X, Yan H, Hu Z. Effect of samarium (Sm) addition on the microstructures and mechanical properties of Al-7Si-0.7Mg alloys. Journal of Alloys and Compounds, 2013, 567(15): 77-81.

[22] Zhang Y, Huang X F, Ma Z D, et al. The influences of Al content on the microstructure and mechanical properties of as-cast $\mathrm{Mg}-6 \mathrm{Zn}$ magnesium alloys. Materials Science \& Engineering A, 2017, 686: 93-101.

[23] Du Y Z, Qiao X G, Zheng M Y, et al. Effect of microalloying with Ca on the microstructure and mechanical properties of Mg- 6 mass $\% \mathrm{Zn}$ alloys. Materials and Design, 2016, 98: 285-293.

[24] Chen T J, Zhang D H, Wang W, et al. Effects of $Y$ content on microstructures and mechanical properties of as-cast $\mathrm{Mg}-\mathrm{Zn}-\mathrm{Nd}$ alloys. China Foundry, 2015,12(5): 339-348.

[25] Balasubramani N. Optimization of heat treatment parameters in ZA84 magnesium alloy. Journal of Alloys and Compounds, 2008 457(1-2): 118-123.

[26] Unsworth W. New magnesium alloys for automobile applications. Light Metal Age, 1987, 45(7-8): 10-13.

[27] Sung H P, Jung J G, Yoon J, et al. Influence of Sn addition on the microstructure and mechanical properties of extruded Mg-8Al-2Zn alloy. Materials Science and Engineering A, 2015, 626: 128-135.

[28] Bai Y, Fang C F, Hao H, et al. Effects of yttrium on microstructure and mechanical properties of $\mathrm{Mg}-\mathrm{Zn}-\mathrm{Cu}-\mathrm{Zr}$ alloys. Transactions of Nonferrous Metals Society of China, 2010, 20(s2): 357-360.

[29] Acer E, Çadırl E, Erol H, et al. Effect of heat treatment on the microstructures and mechanical properties of Al-5.5Zn-2.5Mg alloy. Materials Science \& Engineering A, 2016, 662: 144-156

[30] Yang M B, Wu D Y, Hou M D, et al. As-cast microstructures and mechanical properties of Mg- $4 \mathrm{Zn}-x \mathrm{Y}-1 \mathrm{Ca}(x=1.0,1.5,2.0,3.0)$ magnesium alloys. Transactions of Nonferrous Metals Society of China, 2015, 25(3): 721-731. 